\title{
UV-C LED Irradiation Reduces Salmonella on Chicken and Food Contact Surfaces
}

\author{
Alexandra Calle ${ }^{1, *(\mathbb{D})}$, Mariana Fernandez ${ }^{1}$, Brayan Montoya ${ }^{2}$, Marcelo Schmidt ${ }^{1}$ and Jonathan Thompson ${ }^{3}$ (D) \\ 1 School of Veterinary Medicine, Texas Tech University, 7671 Evans Dr, Amarillo, TX 79106, USA; \\ Mariana.fernandez@ttu.edu (M.F.); Marcelo.schmidt@ttu.edu (M.S.) \\ 2 Escuela de Medicina Veterinaria, Universidad Nacional de Costa Rica, Lagunilla, Heredia 40101, Costa Rica; \\ brayan.montoya.torres@est.una.ac.cr \\ 3 Department of Chemistry, Texas Tech University, MS 1061, Lubbock, TX 79409, USA; jon.thompson@ttu.edu \\ * Correspondence: alexandra.calle@ttu.edu; Tel.: +1-806-834-4074
}

Citation: Calle, A.; Fernandez, M.;

Montoya, B.; Schmidt, M.; Thompson, J. UV-C LED Irradiation Reduces Salmonella on Chicken and Food Contact Surfaces. Foods 2021, 10, 1459. https://doi.org/10.3390/foods10071459

Academic Editor:

Juana Fernández-López

Received: 6 May 2021

Accepted: 22 June 2021

Published: 24 June 2021

Publisher's Note: MDPI stays neutral with regard to jurisdictional claims in published maps and institutional affiliations.

Copyright: (c) 2021 by the authors. Licensee MDPI, Basel, Switzerland. This article is an open access article distributed under the terms and conditions of the Creative Commons Attribution (CC BY) license (https:/ / creativecommons.org/licenses/by/ $4.0 /)$.

\begin{abstract}
Ultraviolet (UV-C) light-emitting diode (LED) light at a wavelength of 250-280 nm was used to disinfect skinless chicken breast (CB), stainless steel (SS) and high-density polyethylene (HD) inoculated with Salmonella enterica. Irradiances of $2 \mathrm{~mW} / \mathrm{cm}^{2}(50 \%)$ or $4 \mathrm{~mW} / \mathrm{cm}^{2}(100 \%)$ were used to treat samples at different exposure times. Chicken samples had the lowest Salmonella reduction with 1.02 and $1.78 \mathrm{Log} \mathrm{CFU} / \mathrm{cm}^{2}(p \leq 0.05)$ after 60 and $900 \mathrm{~s}$, respectively at $50 \%$ irradiance. Higher reductions on CB were obtained with $100 \%$ illumination after $900 \mathrm{~s}\left(>3.0 \mathrm{Log} \mathrm{CFU} / \mathrm{cm}^{2}\right)$. Salmonella on SS was reduced by 1.97 and $3.48 \mathrm{Log}$ CFU $/ \mathrm{cm}^{2}$ after $60 \mathrm{~s}$ of treatment with $50 \%$ and $100 \%$ irradiance, respectively. HD showed a lower decrease of Salmonella, but still statistically significant $(p \leq 0.05)$, with 1.25 and $1.77 \mathrm{Log}$ CFU $/ \mathrm{cm}^{2}$ destruction for 50 and $100 \%$ irradiance after $60 \mathrm{~s}$, respectively. Longer exposure times of HD to UV-C yielded up to $99.999 \%\left(5.0 \mathrm{Log} \mathrm{CFU} / \mathrm{cm}^{2}\right)$ reduction of Salmonella with both irradiance levels. While UV-C LED treatment was found effective to control Salmonella on chicken and food contact surfaces, we propose three mechanisms contributing to reduced efficacy of disinfection: bacterial aggregation, harboring in food and work surface pores and light absorption by fluids associated with CB.
\end{abstract}

Keywords: UV-C; Salmonella; chicken; microbial intervention; food-contact surfaces

\section{Introduction}

Salmonella sp. is a major public health concern and a common food safety hazard associated with poultry processing [1-4]. Foodborne illness caused by this microorganism is one of the most frequent diseases affecting millions of people worldwide every year. Outbreaks related to Salmonella in poultry are very frequent $[1,2,5]$. A recent report by the Centers for Disease Control and Prevention (CDC), between 2015 and 2017, stated that poultry was associated with 262 outbreaks, 4807 illnesses, 849 hospitalizations and 12 deaths in the United States [6]. Salmonella is usually carried by live animals in their gastrointestinal track and transferred to processing environments where end-products can become contaminated [7,8]. Consistently, the presence of Salmonella in poultry houses is also very common with up to $100 \%$ prevalence among surveyed operations [9]. Efforts to control this pathogen are constantly made by the industry and government [10]. The most typical interventions to reduce Salmonella in poultry products involve the application of chemical treatments at different steps of processing, which include the use of organic acids, inorganic compounds, chlorine-based treatments, phosphate-based products, among other chemical compounds [11]. Consumers of poultry seem to have adverse opinions about the use of such chemicals in food [12], creating a challenge for the food industry to control bacterial contaminants. Therefore, poultry facilities would benefit from having alternative technologies to chemical interventions for pathogen control in food and processing environment. 
The use of ultraviolet light has been proven to be effective for microbial inactivation by damaging bacterial DNA [13-15]. Pathogens absorb the ultraviolet (UV) light and thymine dimers are formed, blocking transcription and replication, which ultimately lead to cell death $[15,16]$. There is a growing interest in the use of UV treatments for the inactivation of pathogens in food [17]. The use of UV light in the food industry gained interest after the approval by the Food \& Drug Administration (FDA) in 1997 to use UV irradiation as an alternative for microbial control in meat products $[18,19]$. Today, applications of UV light are commonly used to control pathogens in water, for decontamination of food contact surfaces (bakeries, dairy, and meat plants), and for decontamination of food packaging materials (boxes, bottles, leads, food wrapping films, thermoformable plastics, cartons for liquid foods and others) [19]. Commercially available equipment can be found advertised to disinfect surfaces, but most of the applications pertain to treating drinking water or being used for washing food products.

Several studies have demonstrated the effectiveness of using this technology in a wide variety of food products, such as fresh berries, apple juice, milk, fresh fish, processed meats, and in water [16,20-24]. Similarly, several studies have investigated the use UV light produced by mercury lamps, demonstrating the effectiveness of this technology in a wide variety of food products. However, mercury lamps require high voltage power supplies for operation, and certain lamps produce deep UV radiation of $\lambda<240 \mathrm{~nm}$ that generates significant quantities of ozone, a very reactive oxidative gas harmful to human health and food quality. UV light-emitting diodes (LED) are increasingly being used as substitutes for mercury lamps for several reasons. UV LEDs are much smaller than mercury lamps and generate less heat. As a result, they may be placed close to food contact surfaces to achieve high irradiance, and presumably more effective inactivation of pathogens. In addition, the emission spectrum of UV LEDs can be tuned to emit UV light specifically of wavelengths between 250-280 nm, which are most effective at driving the photochemical reactions leading to formation of thymine dimers. Considering the need to control Salmonella in poultry operations, this research aimed to evaluate the effectiveness of UV-C LED light for the reduction of Salmonella sp. applied to the surface of chicken breasts (CB), stainless steel (SS), and high-density polyethylene (HD) using different times and irradiance intensities.

\section{Materials and Methods}

\subsection{Bacterial Cultures}

A five-strain Salmonella cocktail was prepared with Salmonella Thyphimurium ATCC BAA-712, Salmonella Newport ATCC 6962 (food poisoning fatality), Salmonella Enteritidis ATCC 31194, Salmonella Senftenberg ATCC 43845, and Salmonella Heidelberg ATCC 8326. Each strain was grown individually by transferring $10 \mu \mathrm{L}$ from the stock culture into 9-mL of Tryptic Soy Broth (TSB) (EMD Millipore Chemicals; Darmstadt, Germany) and incubating for $24 \mathrm{~h}$ at $37^{\circ} \mathrm{C}$. Equal amounts $(2 \mathrm{~mL})$ from each grown Salmonella suspension were combined into a sterile test tube and homogenized. The bacterial cocktail was freshly prepared prior each repetition. Salmonella concentration in the cocktail was confirmed at each repetition of the experiment by conducting serial dilutions and plating onto Trypticase Soy Agar (TSA) (Becton, Dickinson and Company, Franklin Lakes, NJ, USA), followed by incubation for $24 \mathrm{~h}$ at $37^{\circ} \mathrm{C}$ and subsequent enumeration.

\subsection{UV-C LED Light and Surfaces Subjected to Irradiation}

The ultraviolet type C (UV-C) light used as the irradiation source for this project was a Klaran class LED acquired from Crystal IS Inc. (Green Island, NY, USA). The UV-C LED had a wavelength range of 250-280 nm, $20 \mathrm{~mW}$ power and a viewing angle of 105 degrees. The lamp was operated under forward bias at a maximum $400 \mathrm{~mA}$ current, corresponding to $100 \%$ irradiance, which is the maximum current recommended by the manufacturer. The average irradiance used in this study was either $2 \mathrm{~mW} / \mathrm{cm}^{2}$ (referred in this experiment as $50 \%$ or half irradiance) or $4 \mathrm{~mW} / \mathrm{cm}^{2}$ (referred in this experiment as $100 \%$ or full irradiance). Three different surfaces were treated with UV-C LED irradiation: (1) boneless skinless 
chicken breast (CB), (2) stainless steel (SS) and (3) high density polyethylene (HD). To treat each surface, experiments were carried out on $2 \times 2 \mathrm{~cm}$ coupons used as the experimental units. SS and HD were selected to be treated with the UV-C light since they are commonly used as food-contact surfaces in the poultry processing industry.

\subsection{Chicken Inoculation and Treatment}

Chicken breast was obtained boneless and skinless from a local supermarket. Portions of $2 \times 2 \mathrm{~cm}$ and approximately $4 \mathrm{~mm}$ thick were aseptically cut. The upper surface was inoculated with the five-strain Salmonella cocktail at a target concentration of ca. 6.0 Log $\mathrm{CFU} / \mathrm{cm}^{2}$. The inoculated CB squares were placed on a tray and set under refrigeration for $30 \mathrm{~min}$ to allow for bacterial attachment. Two irradiance conditions, 50 and 100\%, were explored. In all cases, the CB squares were irradiated individually under the UV-C LED source. In the first case (50\% irradiance), the CB squares were treated for varying times with integrated doses of UV-C radiation corresponding to $0-1.8 \mathrm{~J} / \mathrm{cm}^{2}$. For the second treatment (100\% irradiance), the UV-C dose ranged from $0-3.6 \mathrm{~J} / \mathrm{cm}^{2}$. As light intensity scales linearly with drive current, the UV-C irradiance was controlled by metering the drive current of the LED. The exposure times were: 60, 180, 300, 600 and 900 s. An additional control set of samples (inoculated, not irradiated) were considered. Control samples are referred as $0 \mathrm{~s}$.

\subsection{Stainless Steel Inoculation and Treatments}

Stainless Steel 304 (SS, C 0.08\% max., Mn 2.00\% max., P 0.045\% max., S 0.03\% max., Si 0.75\% max., Cr 18.00-20.00\%, Ni 8.00-12.00\%, N 0.10 max., Fe balance), 2 mm thickness was obtained from Agrosuper (Rancagua, Chile). Sterile SS squares were surface inoculated before each experiment. Squares were cleaned, degreased with acetone, flamed with $95 \%$ ethanol, stored in a glass container and autoclaved at $121^{\circ} \mathrm{C}\left(15 \mathrm{lb} / \mathrm{in}^{2}\right)$ for $15 \mathrm{~min}$. Sterile SS squares were surface-inoculated by applying a $20 \mu \mathrm{L}$ aliquot of the five-strain Salmonella cocktail on one side of each $4 \mathrm{~cm}^{2}$ square. A target surface inoculation of $6.5 \log _{10} \mathrm{CFU} / \mathrm{cm}^{2}$ was attempted. The inoculum was completely spread on the entire surface using a sterile 1- $\mu \mathrm{L}$ loop and then let sit for $30 \mathrm{~min}$ under refrigeration to dry and for bacterial attachment. Treatments were performed with both the low and high irradiance cases, applying a spatially averaged irradiance of approximately $2 \mathrm{~mW} / \mathrm{cm}^{2}$ and $4 \mathrm{~mW} / \mathrm{cm}^{2}$, respectively. Irradiation occurred for a period of 15, 30, 45 and $60 \mathrm{~s}$, and additionally for a control set of samples (inoculated, not irradiated). Controls are referred to as $0 \mathrm{~s}$.

\subsection{High Density Polyethylene Inoculation and Treatments}

Kitchen cutting boards (approx. $1 \mathrm{~cm}$ thick) were obtained from the microbiology research lab, which had been previously used to chop meat samples. The cutting boards were intentionally chosen as used to mimic scratched surfaces from processing facilities. Prior to the study, the HD board was cut into $2 \times 2 \mathrm{~cm}$ squares $\left(4 \mathrm{~cm}^{2}\right)$. HD squares were treated and inoculated following the same procedures as with SS. Both the full irradiance $(100 \%)$ and half irradiance $(50 \%)$ cases were considered. Irradiation times included trials for: 30, 60, 90, 120, 150, 180, 300, 600 and 900 s. Additionally, control samples (inoculated, not irradiated) were tested and referred as $0 \mathrm{~s}$.

\subsection{Analysis of Chicken Rinse Fluid}

Fluids associated with CB were analyzed to evaluate whether they could offer a protective coat effect for bacteria by absorbing ultraviolet light. The extent of light absorption by CB juices was studied by ultraviolet-visible (UV-VIS) absorption spectroscopy. A portion of chicken breast was placed in a plastic bag and $10 \mathrm{~mL}$ of deionized water was added to wash the surface of the chicken. A $3 \mathrm{~mL}$ portion of the deionized water was collected and placed into a $1 \mathrm{~cm}$ path length quartz cuvette, and the full UV-VIS absorbance spectrum 
was recorded against a deionized water blank on an Agilent photodiode array spectrometer with $1 \mathrm{~nm}$ spectral resolution.

\subsection{Microbial Analysis}

$\mathrm{CB}$ portions were placed immediately after the treatment into 9-mL Buffered Peptone Water (BPW) (BD BBL ${ }^{\mathrm{TM}}$, Franklin Lakes, NJ, USA) tubes and thoroughly homogenized. Serial dilutions were conducted to facilitate enumeration followed by spread plating on Xylose-Lysine-Tergitol 4 (XLT4) (BD Difco ${ }^{\mathrm{TM}}$ Franklin Lakes, NJ, USA). Inoculated XLT4 plates were incubated for $24 \mathrm{~h}$ at $37^{\circ} \mathrm{C}$. SS and HD squares exposed to the LED UV-C treatment were transferred immediately after the exposure time to sterile conical tubes (50 mL capacity, Corning ${ }^{\mathrm{TM}}$ Falcon $^{\mathrm{TM}}$ ) containing $10 \mathrm{~mL}$ of phosphate-buffered saline solution (PBS, Sigma-Aldrich ${ }^{\circledR}$, Saint Louis, MO, USA), then mixed by vortex motion for $60 \mathrm{~s}$ to transfer the bacterial cells from the surface to the saline solution. The number of viable bacteria in the saline solution was determined by serially diluting with BPW, spread plating on XLT4 plates and incubating for $24 \mathrm{~h}$ at $37^{\circ} \mathrm{C}$. For each surface, colonies were enumerated upon incubation, and final counts were reported as $\mathrm{CFU} / \mathrm{cm}^{2}$ considering the size of $\mathrm{CB}$, SS, and HD coupons of $4 \mathrm{~cm}^{2}$. Control samples were also enumerated following the corresponding protocol.

\subsection{Electron Micrographs}

Scanning electron microscope (SEM) images were taken by the Texas Tech College of Arts and Sciences Microscopy (CASM). Samples were provided to CASM frozen at $-80{ }^{\circ} \mathrm{C}$ with the bacterial cells suspended in sterile water. CB, SS, and HD squares with bacterial cells were dried frozen and coated with Iridium (Ir). SEM imaging were obtained with an electron microscope Zeiss Crossbeam 540 FIB-SEM.

\subsection{Statistical Analysis}

Each surface (CB, SS and HD) treated with the UV-C was subjected to two different treatment combinations that included irradiance and exposure time. Analyses of variance were used to test the effect of time periods (illumination time; measured in seconds) on Salmonella reduction ( $\log \mathrm{CFU} / \mathrm{cm}^{2}$ ) under two levels of irradiance exposure (irradiance), and on three specific surfaces conditions (i.e., chicken breast, stainless steel, and highdensity polyethylene. Three experimental repetitions were conducted and a total of six separate ANOVAs were conducted. Each model revealed a significant $(\alpha=0.05)$ UV-C illumination time effect on Log $\mathrm{CFU} / \mathrm{cm}^{2}$. Multiple comparisons were calculated using Bonferronni correction to determine differences at each level of the illumination time variable. All statistical analyses were conducted with STATA (StataCorp. 2019. Stata Statistical Software: Release 16. College Station, TX, USA: StataCorp LLC.).

\section{Results and Discussion}

LED UV-C treatment was applied to inactivate Salmonella sp. deposited on three different surfaces: chicken breast (CB), type 304 stainless steel (SS) and high-density polyethylene (HD). For all samples tested, two irradiance intensities were tested, $2 \mathrm{~mW} / \mathrm{cm}^{2}(50 \%)$ and $4 \mathrm{~mW} / \mathrm{cm}^{2}(100 \%)$. Illumination times between 0 and $900 \mathrm{~s}$ ( 0 and $\left.15 \mathrm{~min}\right)$ were explored. An overview of the findings per treatment is summarized in Tables 1-3 and discussed below. The UV-C wavelengths used during the experiments were in the range 250-280 nm, which are considered safe for food products according to the FDA permitted levels of $253.7 \mathrm{~nm}$ [25]; however, this regulation only refers to the use of mercury lamps and not LED lamps. 
Table 1. Salmonella reduction on chicken breast.

\begin{tabular}{|c|c|c|c|c|c|c|}
\hline $\begin{array}{l}\text { Illumination } \\
\text { Time (s) }\end{array}$ & $\begin{array}{c}\text { Irradiance }^{1} \\
\left(\mathrm{~mW} / \mathrm{cm}^{2}\right)\end{array}$ & $\begin{array}{l}\text { UV }^{4} \text { Dose } \\
\left(\mathrm{J} / \mathrm{cm}^{2}\right)\end{array}$ & $\begin{array}{l}\text { Bacterial } \\
\text { Count (Log } \\
\left.\text { CFU } / \mathrm{cm}^{2}\right)\end{array}$ & St. Dev. ${ }^{5}$ & $\begin{array}{c}\text { Reduction }^{2} \\
\left(\log \mathrm{CFU} / \mathrm{cm}^{2}\right)\end{array}$ & $\begin{array}{c}\text { Bacterial } \\
\text { Reduction }(\%)^{3}\end{array}$ \\
\hline 0 & 2 & 0 & 6.21 & 0.16 & - & - \\
\hline 60 & 2 & 0.12 & 5.20 & 0.48 & 1.01 & 90.2 \\
\hline 180 & 2 & 0.36 & 4.89 & 0.81 & 1.32 & 95.2 \\
\hline 300 & 2 & 0.60 & 4.64 & 0.67 & 1.57 & 97.3 \\
\hline 600 & 2 & 1.20 & 4.36 & 0.70 & 1.85 & 98.6 \\
\hline 900 & 2 & 1.80 & 4.43 & 0.70 & 1.78 & 98.3 \\
\hline 0 & 4 & 0 & 6.26 & 0.11 & - & - \\
\hline 60 & 4 & 0.24 & 4.21 & 0.77 & 2.05 & 99.1 \\
\hline 180 & 4 & 0.72 & 3.99 & 0.86 & 2.27 & 99.5 \\
\hline 300 & 4 & 1.2 & 3.67 & 0.63 & 2.59 & 99.7 \\
\hline 600 & 4 & 2.4 & 3.89 & 0.44 & 2.37 & 99.6 \\
\hline 900 & 4 & 3.6 & 3.25 & 0.53 & 3.01 & 99.9 \\
\hline
\end{tabular}

${ }^{1}$ Irradiance of 2 and $4 \mathrm{~mW} / \mathrm{cm}^{2}$ are equivalent to 50 and $100 \%$, respectively. ${ }^{2}$ Reduction based on the initial attachment at time 0 .

${ }^{3}$ Percentage calculated using actual values of colony forming units (CFU) before log transformation. ${ }^{4}$ Ultraviolet. ${ }^{5}$ Standard Deviation.

Table 2. Salmonella reduction on stainless steel.

\begin{tabular}{|c|c|c|c|c|c|c|}
\hline $\begin{array}{l}\text { Illumination } \\
\text { Time (s) }\end{array}$ & $\begin{array}{c}\text { Irradiance }^{1} \\
\left(\mathrm{~mW} / \mathrm{cm}^{2}\right)\end{array}$ & $\begin{array}{l}\text { UV Dose } \\
\left(\mathrm{J} / \mathrm{cm}^{2}\right)\end{array}$ & $\log \mathrm{CFU} / \mathrm{cm}^{2}$ & St. Dev. & $\begin{array}{c}\text { Reduction }^{2} \\
\left(\text { Log CFU/cm }{ }^{2}\right)\end{array}$ & $\begin{array}{c}\text { Bacterial } \\
\text { Reduction (\%) }\end{array}$ \\
\hline 0 & 2 & 0 & 3.4 & 0.61 & - & - \\
\hline 15 & 2 & 0.03 & 2.1 & 0.72 & 1.3 & 93.7 \\
\hline 30 & 2 & 0.06 & 1.94 & 0.83 & 1.46 & 95.6 \\
\hline 45 & 2 & 0.09 & 1.87 & 0.72 & 1.53 & 96.3 \\
\hline 60 & 2 & 0.12 & 1.43 & 0.41 & 1.97 & 98.7 \\
\hline 0 & 4 & 0 & 6.27 & 0.49 & - & - \\
\hline 15 & 4 & 0.06 & 4.91 & 0.56 & 1.36 & 95.6 \\
\hline 30 & 4 & 0.12 & 3.78 & 1.5 & 2.49 & 99.7 \\
\hline 45 & 4 & 0.18 & 3.47 & 0.65 & 2.8 & 99.8 \\
\hline 60 & 4 & 0.24 & 2.79 & 1.76 & 3.48 & 99.9 \\
\hline
\end{tabular}

${ }^{1}$ Irradiance of 2 and $4 \mathrm{~mW} / \mathrm{cm}^{2}$ are equivalent to 50 and $100 \%$, respectively. ${ }^{2}$ Reduction based on the initial attachment at time 0 . ${ }^{3}$ Percentage calculated using actual values of colony forming units (CFU) before log transformation. St. Dev. refers to standard deviation and UV refers to ultraviolet.

\subsection{Boneless Skinless Chicken Breast (CB)}

Results for reduction of Salmonella on CB are reported in Table 1. For the CB treated with $50 \%$ irradiance, initial bacterial attachment was estimated to be $6.21 \pm 0.16 \mathrm{Log} \mathrm{CFU} / \mathrm{cm}^{2}$. Significant $(p \leq 0.05)$ reductions of Salmonella were obtained after each of the treatment times $(60,180,300,600$ and $900 \mathrm{~s})$ compared to the starting inoculation level. After $60 \mathrm{~s}$ of exposure, Salmonella decreased by $1.02 \log \mathrm{CFU} / \mathrm{cm}^{2}$, which was significant at $p \leq 0.05$. Upon completion of a 900 s irradiance, a total Salmonella reduction of $1.78 \mathrm{Log} \mathrm{CFU} / \mathrm{cm}^{2}(p \leq 0.05)$ was achieved.

On the other hand, when CB was treated with $100 \%$ irradiance the reduction of Salmonella was enhanced. Considering the initial attachment level of Salmonella observed in the samples $\left(6.26 \pm 0.11 \log \mathrm{CFU} / \mathrm{cm}^{2}\right)$, significant $(p \leq 0.05)$ reductions were also obtained after each treatment time relative to the Salmonella level before treatments. Data show a total reduction of $>3.0 \mathrm{Log} \mathrm{CFU} / \mathrm{cm}^{2}$ during the total exposure time $(900 \mathrm{~s})$. Based on the data obtained at the different time points, the rate of reduction of Salmonella occurred most efficiently within the first $60 \mathrm{~s}$ of UV illumination. During this time, Salmonella was reduced by $2.05 \mathrm{Log} \mathrm{CFU} / \mathrm{cm}^{2}$, which was significant at $p \leq 0.05$. After that first minute of UV-C exposure, Salmonella was reduced only by an additional $0.96 \mathrm{Log} \mathrm{CFU} / \mathrm{cm}^{2}$ total, which was still significant at $p \leq 0.05$. Comparable results were found by McLeod et al. [26]. In their investigation using $254 \mathrm{~nm}$ wavelength, skinless chicken fillets were exposed for 5 , 
10, 30, 60 and $300 \mathrm{~s}$. After the first $60 \mathrm{~s}$ of treatment, they were able to observe a Salmonella reduction of $1.5 \mathrm{Log} \mathrm{CFU} / \mathrm{cm}^{2}$. However, when the exposure was $300 \mathrm{~s}$, a $2.4 \mathrm{Log} \mathrm{CFU} / \mathrm{cm}^{2}$ reduction was achieved.

Table 3. Salmonella reduction on high density polyethylene.

\begin{tabular}{|c|c|c|c|c|c|c|}
\hline $\begin{array}{l}\text { Illumination } \\
\text { Time (s) }\end{array}$ & $\begin{array}{c}\text { Irradiance }^{1} \\
\left(\mathrm{~mW} / \mathrm{cm}^{2}\right)\end{array}$ & $\begin{array}{l}\text { UV Dose } \\
\left(\mathrm{J} / \mathrm{cm}^{2}\right)\end{array}$ & $\begin{array}{c}\log \\
\mathrm{CFU} / \mathrm{cm}^{2}\end{array}$ & St. Dev. & $\begin{array}{c}\text { Reduction }^{2} \\
\left(\log \text { CFU } / \mathrm{cm}^{2}\right)\end{array}$ & $\begin{array}{c}\text { Bacterial } \\
{\text { Reduction }(\%)^{3}}^{3}\end{array}$ \\
\hline 0 & 2 & 0 & 6.58 & 0.16 & - & - \\
\hline 30 & 2 & 0.06 & 5.67 & 0.28 & 0.91 & 87.7 \\
\hline 60 & 2 & 0.12 & 5.33 & 0.12 & 1.25 & 94.4 \\
\hline 90 & 2 & 0.18 & 5.28 & 0.17 & 1.3 & 95.0 \\
\hline 120 & 2 & 0.24 & 5.13 & 0.16 & 1.45 & 96.5 \\
\hline 150 & 2 & 0.30 & 5.05 & 0.25 & 1.53 & 97.0 \\
\hline 180 & 2 & 0.36 & 4.57 & 0.47 & 2.01 & 99.0 \\
\hline 300 & 2 & 0.6 & 2.75 & 1.68 & 3.83 & 99.99 \\
\hline 600 & 2 & 1.2 & 2.04 & 1.68 & 4.54 & 99.997 \\
\hline 900 & 2 & 1.8 & 1.84 & 1.46 & 4.74 & 99.998 \\
\hline 0 & 4 & 0 & 5.20 & 0.15 & - & - \\
\hline 30 & 4 & 0.12 & 3.97 & 0.24 & 1.23 & 94.1 \\
\hline 60 & 4 & 0.24 & 3.43 & 0.24 & 1.77 & 98.3 \\
\hline 90 & 4 & 0.36 & 2.82 & 0.29 & 2.38 & 99.6 \\
\hline 120 & 4 & 0.48 & 2.42 & 0.07 & 2.78 & 99.8 \\
\hline 150 & 4 & 0.60 & 2.40 & 0.00 & 2.8 & 99.8 \\
\hline 180 & 4 & 0.72 & 0 * & 0 * & 5.2 & 99.999 \\
\hline 300 & 4 & 1.20 & 0 * & 0 * & 5.2 & 99.999 \\
\hline 600 & 4 & 2.40 & 0 * & 0 * & 5.2 & 99.999 \\
\hline 900 & 4 & 3.60 & 0 * & 0 * & 5.2 & 99.999 \\
\hline
\end{tabular}

${ }^{1}$ Irradiance of 2 and $4 \mathrm{~mW} / \mathrm{cm}^{2}$ are equivalent to 50 and $100 \%$, respectively. ${ }^{2}$ Reduction based on the initial attachment at time 0 . ${ }^{3}$ Percentage calculated using actual values of colony forming units (CFU) before log transformation. St. Dev. refers to standard deviation and UV refers to ultraviolet. ${ }^{*}$ No colonies recovered.

There are three hypothesis we propose for this outcome. First, the porosity of the chicken surface could play an important role in the reduced effect of the UV-C against Salmonella. An image of the boneless skinless chicken breast sample used during this research was obtained via electron microscopy (Figure 1). The chicken surface may visually appear smooth; however, cracks, crevices, and/or pores could protect bacterial cells from light exposure [26]. A single Salmonella cell is $2-5 \mu \mathrm{m}$ long by $0.5-1.5 \mu \mathrm{m}$ wide [27], thus the micro holes in the chicken breast, as observed in the electron micrograph (Figure 1A), could harbor bacterial cells. Some cells may become trapped or sequestered within the irregular and porous surface of the chicken, which may affect the effectiveness of the UV-C to evenly cover and reach the entire surface area of the sample as seen in Figure 1B,C. As described by Lagunas-Solar et al. [28], complex surface properties of foods bring a challenge; microorganisms located in pores and crevices of a food surface can be shaded from light, and thus remain unaffected. The use of UV light can be more effective to reduce microorganisms on foods with smooth surfaces such as fresh whole fruits, vegetables, hard cheese, and smooth-surface meat slices [29].

The second hypothesis for reduced efficacy of UV illumination after the initial minute is that the fluid on the surface associated with $\mathrm{CB}$ absorbs ultraviolet radiation, reducing the light intensity and thereby reducing the rate of bacterial deactivation. To support this premise, the UV-VIS absorption spectrum of the fluid associated with the chicken breast samples was obtained. It was found that the fluid strongly absorbs ultraviolet light below $300 \mathrm{~nm}$, and this light absorption will lower the intensity of light interacting with Salmonella, offering a protective or shielding effect to prevent deactivation (see Section 3.5). The presence of fluids between bacterial cells and the light, most likely affects the efficacy of the treatment as the liquid may absorb the light $[26,30]$. 


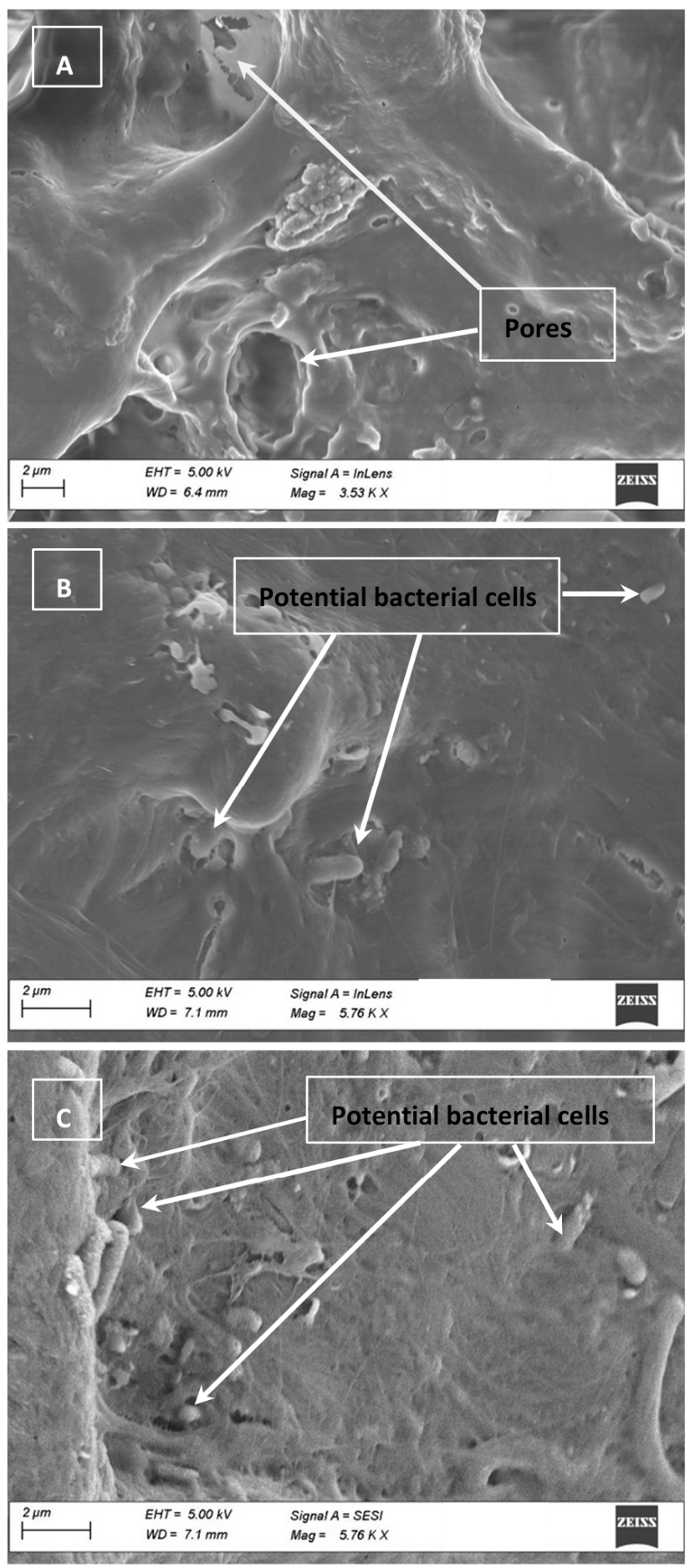

Figure 1. Electron micrograph of chicken breast samples illustrating the porous nature of the chicken (A). Salmonella, being only $2-5 \mu \mathrm{m}$ long by $0.5-1.5 \mu \mathrm{m}$ wide may enter pores on the surface of the chicken and be sheltered from full illumination (see $(\mathbf{B}, \mathbf{C}))$.

The third hypothesis involves the tendency for cells to aggregate into clusters. When illuminated, cells near the surface of the cluster (nearest to LED) may absorb the UV radiation and be inactivated. However, cells located beneath the top layer may be shaded from full illumination and protected. The premise for this mechanism of bacterial cell protection during UV irradiation has been presented recently in the literature [31]. 


\subsection{Stainless Steel (SS)}

The reduction of Salmonella was evaluated at intervals of $15 \mathrm{~s}$ during a period of $60 \mathrm{~s}$, and the summary of the findings is presented in Table 2. For experiments with $50 \%$ irradiance, the initial attachment level of Salmonella on the SS squares was only $3.4 \pm 0.61 \mathrm{Log} C F U / \mathrm{cm}^{2}$. Results indicate that a rapid reduction $\left(1.3 \mathrm{Log} \mathrm{CFU} / \mathrm{cm}^{2}\right)$ of Salmonella occurred after the first $15 \mathrm{~s}$ of exposure to UV light, which was statistically different $(p \leq 0.05)$ from the starting level. When the total exposure time of $60 \mathrm{~s}$ was applied, a reduction of $1.97 \mathrm{Log} \mathrm{CFU} / \mathrm{cm}^{2}(p \leq 0.05)$ was observed.

In the case of experiments with 100\% irradiance, SS was inoculated with an average load of $6.26 \pm 0.49 \mathrm{Log}$ CFU $/ \mathrm{cm}^{2}$ of Salmonella. A loss of approx. $1.36 \mathrm{Log} \mathrm{CFU} / \mathrm{cm}^{2}$ Salmonella occurred within the first $15 \mathrm{~s}$ of illumination, and nearly $2.49 \log \mathrm{CFU} / \mathrm{cm}^{2}$ was reduced after $30 \mathrm{~s}$ of exposure to the UV LED. These reductions were statistically significant at $p \leq 0.05$. The reduction of Salmonella over time on SS did not plateau and level-off, but rather a decrease in numbers continued through the entire duration of the experiment. The highest reduction was observed after $60 \mathrm{~s}$ of UV-C exposure (3.48 Log CFU $\left./ \mathrm{cm}^{2}\right)$. Lim and Harrison [14] evaluated the effect of UV-C (254 nm) in reducing Salmonella contamination on $3 \times 5 \mathrm{~cm}$ stainless steel coupons. They obtained reductions of 2.75 and $3.51 \log \mathrm{CFU} /$ coupon of $15 \mathrm{~cm}^{2}$ after treatment times of 5 and $30 \mathrm{~s}$, respectively. Bae and Lee [32] exposed stainless steel for longer periods and found reductions of 1.25 and $2.02 \mathrm{Log} C F U /$ coupon of $5 \times 2 \mathrm{~cm}$ after $30 \mathrm{~min}$ and $1 \mathrm{~h}$, respectively. While it appears that their investigation suggests a low effectiveness of the UV treatment, it is important to mention that their group used a UV $253.7 \mathrm{~nm}$ wavelength with intensity of $0.236 \pm 0.013 \mathrm{~mW} / \mathrm{cm}^{2}$, which was much lower than the irradiance used in the current research ( 2 or $\left.4 \mathrm{~mW} / \mathrm{cm}^{2}\right)$. Consistent reductions were also observed by Sommers et al. [30]. Their findings indicate a Salmonella reduction of $5 \mathrm{Log}$ CFU/coupon on stainless steel when inoculated coupons were exposed to UV-C at a dose of $400 \mathrm{~mJ} / \mathrm{cm}^{2}$. When inoculated coupons were treated with $50 \mathrm{~mJ} / \mathrm{cm}^{2}$, the pathogens were reduced by only 1.86-3.05 Log CFU/coupon. Kim et al. [31] found that UV-C intensities of 250 or $500 \mu \mathrm{W} / \mathrm{cm}^{2}$ decreased three target microorganisms (L. monocytogenes, S. typhimurium, and E. coli O157:H7) on stainless steel surfaces. A UV-C dose of $90 \mathrm{~mJ} / \mathrm{cm}^{2}$ reduced the three pathogens by $>4 \mathrm{Log}$ $\mathrm{CFU} /$ coupon; however, a dose of $15 \mathrm{~mJ} / \mathrm{cm}^{2}$ decreased the pathogens by 2.43-4.38 Log $\mathrm{CFU} /$ sample. These doses and times were considerably higher (1,2, and $3 \mathrm{~min})$ compared to those use in the current research.

Based on the above cited investigations, it may be possible to increase the rate of Salmonella destruction by increasing exposure times. To investigate whether the porosity of the SS surface causes harboring of cells, electron micrographs of the SS coupons used during the present experiment were obtained (Figure 2). The images show minor surface imperfections. Although the depth can't be determined, the apparent size of the crevice may not be large enough to harbor Salmonella cells (Figure 2A). An agglomeration of cells was also observed (Figure 2B), forming horizontal and vertical layers of cells (Figure 2C).

\subsection{High Density Polyethylene (HD)}

Salmonella reduction was observed when HD was treated with UV-C, as presented in Table 3. For the treatment of HD with 50\% irradiance, the initial inoculation level was $6.58 \pm 0.16 \mathrm{Log} \mathrm{CFU} / \mathrm{cm}^{2}$. After $30 \mathrm{~s}$ of exposure, Salmonella was reduced by nearly $1 \mathrm{Log} \mathrm{CFU} / \mathrm{cm}^{2}(p>0.05)$; however, only after $150 \mathrm{~s}$ of irradiation was a significant $(p \leq 0.05)$ reduction in Salmonella obtained. Disinfection on the HD surface followed a different temporal pattern compared to CB, as statistically significant reduction of Salmonella continued to be achieved after even several minutes of illumination. This result suggests the Salmonella on HD surfaces may not experience the shielding effect proposed for the $\mathrm{CB}$ samples (vide supra). 

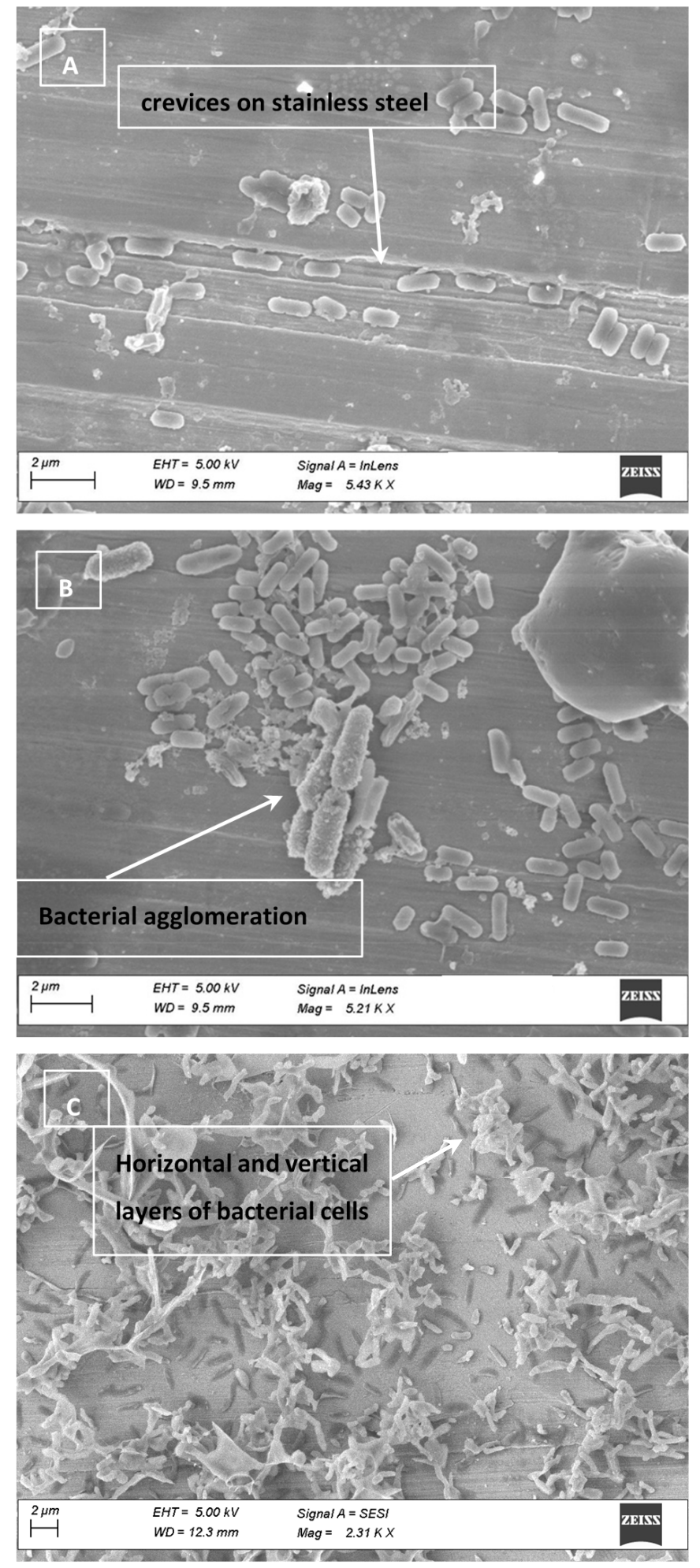

Figure 2. Electron micrograph of stainless steel (SS) inoculated with Salmonella showing imperfections on SS (A) and agglomeration of the cells on the surface (B). Vertical and horizontal agglomerations were observed when high volumes of cells are present $(\mathbf{C})$.

When HD squares were treated with $100 \%$ irradiance, Salmonella was also effectively reduced. The initial attachment level of the microorganism was $5.20 \pm 0.15 \mathrm{Log} C \mathrm{FU} / \mathrm{cm}^{2}$. Experimental data showed a statistically significant $(p \leq 0.05)$ reduction of $1.77 \mathrm{Log} \mathrm{CFU} / \mathrm{cm}^{2}$ during the first $60 \mathrm{~s}$ of exposure, with approximately $1.23 \mathrm{Log} \mathrm{CFU} / \mathrm{cm}^{2}$ reduction $(p>0.05)$ 
occurring within the initial $30 \mathrm{~s}$. Lim and Harrison [14] obtained similar results when they exposed $35 \mathrm{~cm}$ high density polyethylene coupons inoculated with Salmonella. After 5 and $30 \mathrm{~s}$ of treatment with UV-C light $(254 \mathrm{~nm})$, the reduction of Salmonella was 2.93 and $4.32 \mathrm{Log}$ CFU/coupon of $15 \mathrm{~cm}^{2}$, respectively. In 2011, Haughton et al. [33] treated nine different food contact surfaces (black \& white polypropylene, polystyrene, aluminum, polyethylene-polypropylene blend, polyolefin, polyvinyl chloride, stainless steel, polyethylene) with UV-C does ranging from $0-192 \mathrm{~mJ} / \mathrm{cm}^{2}$. The authors found that C. jejuni, E. coli, and Salmonella could be reduced by $>2 \log \mathrm{CFU} / \mathrm{cm}^{2}$ on all surfaces during treatment. However, substantial differences in disinfection efficacy were noted for different materials. For the polyethylene cutting board tested, a UV-C dose of $<20 \mathrm{~mJ} / \mathrm{cm}^{2}$ was effective at inactivating the bacteria to levels below the limit of detection. Bae and Lee [32] obtained reductions of 1.62 and $1.18 \mathrm{Log}$ CFU/coupon of $5 \times 2 \mathrm{~cm}$ after $30 \mathrm{~min}$ and $1 \mathrm{~h}$ of UV treatment. Although the authors reported statistically significant reductions relative to the level of Salmonella before treatments, they were considerably lower than the reductions found in the present research.

Longer exposure times yielded much higher inactivation levels of Salmonella. After $180 \mathrm{~s}$ of treatment, no Salmonella was recovered from the samples in any of the repetitions. To confirm the inactivation of Salmonella, samples exposed to the UV-C treatment during 180, 300, 600 and $900 \mathrm{~s}$ were enriched in 10-mL BPW, incubated overnight at $37^{\circ} \mathrm{C}$, and streaked onto XLT4. After $24 \mathrm{~h}$ of incubation at $37^{\circ} \mathrm{C}$ no Salmonella colonies were recovered. Sommers, et al. [34] inoculated both stainless steel and HDPE surfaces with F. tularensis in food exudate prior to treating with UV-C. These authors found that exposure to $500 \mathrm{~mJ} / \mathrm{cm}^{2}$ reduced the pathogen level by $>4 \log \mathrm{CFU} /$ coupon for both surfaces. However, their treatment was at a higher UV dose, and it is possible that $F$. tularensis is less sensitive to UV treatment compared to Salmonella.

Electron micrograph of the HD coupons used during these experiments were obtained. As depicted in Figure 3, deep crevices were observed (Figure 3A,B), which could potentially hide bacterial cells. These crevices may be associated with use of the board for cutting. Clumping of cells was observed (Figure 3C). Thus, reductions obtained when the UV dose was $>0.72 \mathrm{~J} / \mathrm{cm}^{2}$, indicate that the quality of the surface may not have affected bacterial survival.

Only in the case of HD did the UV dose seem to show consistent reductions regardless of what combinations of irradiance and time were used to achieve the given dose. For example, when the UV dose was $0.12 \mathrm{~J} / \mathrm{cm}^{2}$, a reduction of 1.25 and $1.23 \mathrm{Log} \mathrm{CFU} / \mathrm{cm}^{2}$ was observed at 50 and $100 \%$ illumination, respectively. Similar cases were observed with $0.24,0.36$, and $1.2 \mathrm{~J} / \mathrm{cm}^{2}$ as observed in Table 3 . This appears to follow the BunsenRoscoe reciprocity law, which suggests that the effectiveness of the irradiation is achieved regardless of what combination of time and irradiation rate is used to reach a certain UV dose exposure (short exposure with high irradiance or long exposure time with high irradiance) [30].

\subsection{Cell Clumping and SEM Images}

SEM images obtained from the inoculated surfaces and chicken are presented in Figures 1-3. On CB and HD, pores were large enough to shelter Salmonella cells. Electron micrographs of SS show clear scratches that are long but apparently not wide or deep enough to harbor Salmonella. As an important finding, SEM images with bacterial cells inoculated on the CB, SS and HD show vertical and horizontal accumulations of cells (clumping or aggregation). The conglomeration of cells may also cause shading and shielding effects, protecting those cells that are below the top layer, as previously mentioned [31]. It can be hypothesized that with a larger concentration of cells on the surfaces, UV-C light penetration could represent a challenge. This possibility should consider the fact that chicken and food contact surfaces could also carry other microorganisms that could potentially cause shielding. 

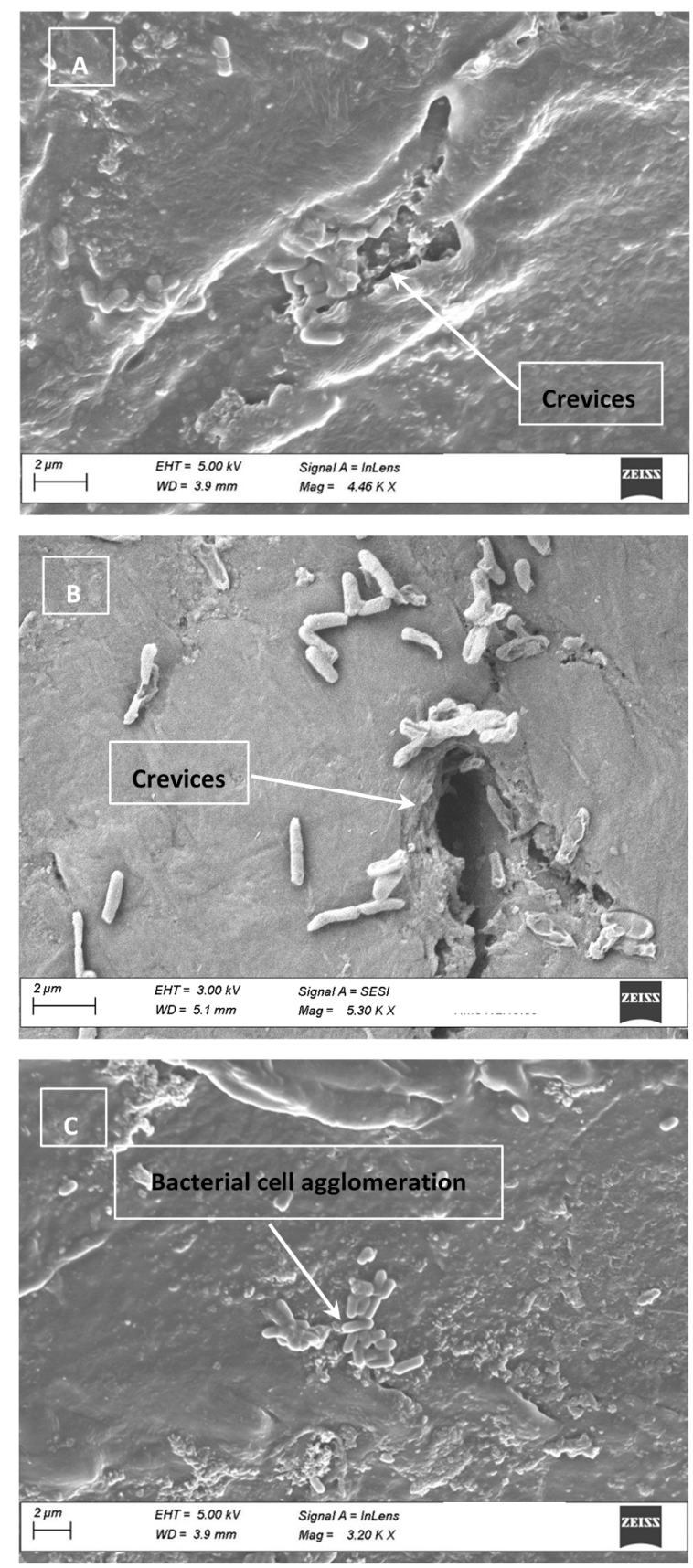

Figure 3. (A-C) Electron micrograph of three different high-density polyethylene (HD) samples used during the experiments. Based on the scale indicated in the micrograph, the crevice highlighted in (B) appears to be large enough to harbor Salmonella cells (rod shaped). (C) depicts bacterial cell agglomerates present on the surface of the HD.

\subsection{Absorption of UV Light by Chicken Rinse Fluid}

An extremely high absorption of light by the fluid present on the chicken at wavelengths lower than $300 \mathrm{~nm}$ was observed. The resulting absorbance spectrum is depicted in Figure 4 . The data suggests that $<0.01 \%$ of light below $290 \mathrm{~nm}$ was transmitted through the $1 \mathrm{~cm}$ path sample used. The fluid associated with the chicken breast absorbs UV light very strongly, and bacteria immersed within this fluid are likely protected or sheltered from photochemical damage caused by irradiation by the LED. This effect may cause the observed rapid initial reduction in bacterial load followed by leveling off between $4-5 \mathrm{Log} C F U / \mathrm{cm}^{2}$. Bacterial cells not well immersed within the fluid may experience full illumination from 
the LED and resultant deactivation, while other bacterial cells more immersed within the fluid/broth are sheltered by the fluid's absorption of light and are protected.

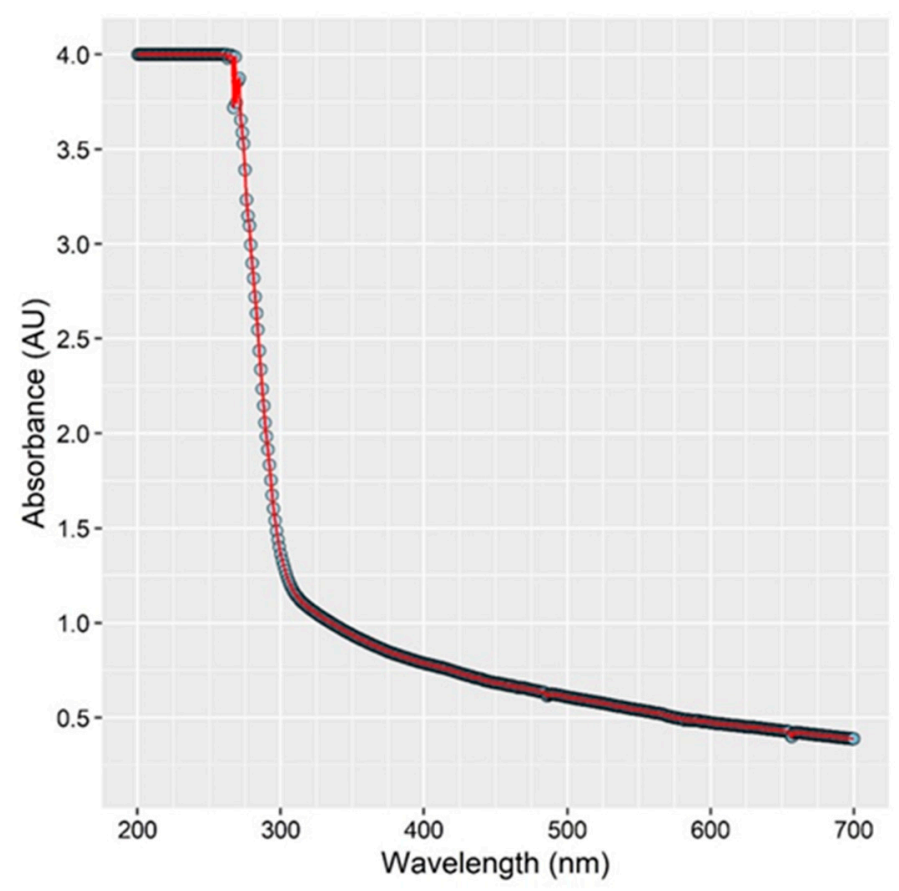

Figure 4. Absorption spectrum of fluid removed from surface of chicken breast (CB). The graph represents the light absorbance of the chicken fluid vs. the wavelength of light. As observed, below $300 \mathrm{~nm}$, the absorption of light increases, which could potentially shelter Salmonella and prevent deactivation.

The effectiveness of UV-C light on disinfecting liquids is known to be dependent on the type of fluid [35]. A low transmittance of UV light is common in fluids other than water due to their tendency to scatter and/or absorb UV light [12]. When liquids have low transmissivity due to the presence of organic compounds, soluble solutes or particulate matter, UV-C disinfection can be challenging [36]. As a point of reference, the penetration depth of some fluid foods (the distance at which $90 \%$ of the light is absorbed) is $0.67,0.25$, $0.22,0.10$ and $0.01 \mathrm{~mm}$ for clear apple cider, apple cider, liquid sucrose, orange juice, and egg whites, respectively [12].

The commercial availability of deep UV-C LEDs has led to an emergence of potential applications in the food processing industry [37,38]. Due to their advantages, LED lamps are now being implemented in systems for water disinfection; however, other uses are currently rare. One exciting application is in the disinfection of food products and food contact surfaces while on the production line. LED devices could be more robust, durable, and portable compared to mercury lamps because there are no glass tubes that may break and contaminate workstations with mercury.

\section{Conclusions}

This study demonstrated the effectiveness of UV-C LED at reducing Salmonella on chicken breast samples and common food contact surfaces such as stainless steel and high-density polyethylene. At a minimum, a $1 \mathrm{Log} \mathrm{CFU} / \mathrm{cm}^{2}$ reduction for $\mathrm{CB}$ was noted in trials, with up to $3 \mathrm{Log} \mathrm{CFU} / \mathrm{cm}^{2}$ being reached. Further reductions seemed to be limited by the remaining Salmonella in the sample being shaded from the UV-C light. This is believed to occur by Salmonella sheltering within pores on the CB surface or behind neighboring bacterial cells, absorption of UV light by fluid present on the $\mathrm{CB}$, or both effects simultaneously. Salmonella was also reduced on both food contact surfaces, yielding reductions up to 3.5 and $5.2 \mathrm{Log} \mathrm{CFU} / \mathrm{cm}^{2}$ on stainless steel and high-density polyethylene, 
respectively. An increase in irradiance yielded higher reductions of Salmonella on food and food contact surfaces with up to $99.999 \%$ in the case of HD.

A clumping cell factor, when large number of bacteria are accumulated on the surfaces, should be considered. Electron micrographs showed formation of layers of Salmonella that extended horizontally and accumulated vertically, which could protect cells beneath the top layer.

UV-C LED illumination could be an effective means to deactivate Salmonella, especially for nonporous surfaces which are not UV light absorbing.

By doubling the irradiance $\left(\mathrm{mW} / \mathrm{cm}^{2}\right)$ from 50 to $100 \%$, the UV dose $\left(\mathrm{J} / \mathrm{cm}^{2}\right)$ deposited on each surface was also increased or duplicated. Larger UV doses were directly correlated with the Salmonella reduction (Log CFU $/ \mathrm{cm}^{2}$ ) attained on each surface tested; however, such reduction did not necessarily double. In other words, Salmonella reductions were consistent with the intensity of exposure but not exactly proportional to the increase in the UV dose.

The majority of research studies investigating the effect of UV treatments to control bacterial pathogens from food or food contact surfaces focus on the use of conventional mercury UV lamps. Since the present investigation found the effectiveness of using UV-C LED light for food and environmental surface treatment, findings could be relevant particularly to the poultry industry. The advantages of UV-C LEDs over chemical treatments and conventional mercury UV should be highlighted when considering UV-C LEDs as an alternative for pathogen control. UV-C LEDs do not contain mercury, are environmentally friendly, robust, durable, energy efficient, and their full illumination power can be reached more rapidly, without time delay for warm-up [39].

Author Contributions: Conceptualization, A.C. and J.T.; methodology, A.C.; formal analysis, M.S.; investigation, M.F., B.M.; resources, A.C.; writing-original draft preparation, A.C. and J.T.; supervision, A.C.; funding acquisition, A.C. All authors have read and agreed to the published version of the manuscript.

Funding: This research received no external funding.

Institutional Review Board Statement: Not applicable.

Informed Consent Statement: Not applicable.

Data Availability Statement: Project data has been reported within this manuscript.

Acknowledgments: The authors want to acknowledge ICFIE laboratory personnel at Texas Tech University for their support during this research project, and Ilan Arvelo for overseeing some experiments conducted by research students. Special acknowledgment to Bo Zhao from CASM for processing samples and capturing SEM images. Acknowledgement of contribution of effort in no way formally implies endorsement of statements made within this manuscript.

Conflicts of Interest: The authors declare no conflict of interest.

\section{References}

1. USDA; FSIS. Serotypes Profile of Salmonella Isolates from Meat and Poultry Products January 1998 through December 2014. 2016. Available online: https://www.fsis.usda.gov/wps/wcm/connect/3866026a-582d-4f0e-a8ce-851b39c7390f/SalmonellaSerotype-Annual-2014.pdf?MOD=AJPERES (accessed on 17 April 2021).

2. Tack, D.M.; Ray, L.; Griffin, P.M.; Cieslak, P.; Dunn, J.; Rissman, T.; Jervis, R.; Lathrop, S.; Muse, A.; Duwell, M.; et al. Preliminary Incidence and Trends of Infections with Pathogens Transmitted Commonly Through Food-Foodborne Diseases Active Surveillance Network, 10 U.S. Sites, 2016-2019. MMWR Morb. Mortal. Wkly. Rep. 2020, 69, 509-514. [CrossRef]

3. Grant, A.; Parveen, S.; Schwarz, J.; Hashem, F.; Vimini, B. Reduction of Salmonella in ground chicken using a bacteriophage. Poult. Sci. J. 2017, 96, 2845-2852. [CrossRef]

4. Cox, N.A.; Richardson, L.J.; Cason, J.A.; Buhr, R.J.; Vizzier-Thaxton, Y.; Smith, D.P.; Fedorka-Cray, P.J.; Romanenghi, C.P.; Pereira, L.V.; Doyle, M.P. Comparison of neck skin excision and whole carcass rinse sampling methods for microbiological evaluation of broiler carcasses before and after immersion chilling. J. Food Prot. 2010, 73, 976-980. [CrossRef] [PubMed]

5. Antunes, P.; Mourão, J.; Campos, J.; Peixe, L. Salmonellosis: The role of poultry meat. Clin. Microbiol. Infect. 2016, $22,110-121$. [CrossRef] 
6. Centers for Disease Control and Prevention (CDC). National Center for Emerging and Zoonotic Infectious Diseases (NCEZID). December 2018. Available online: https://wwwn.cdc.gov/norsdashboard/ (accessed on 17 April 2019).

7. Whyte, P.; Collins, J.D.; McGill, K.; Monahan, C.; O'Mahony, H. Quantitative investigation of the effects of chemical decontamination procedures on the microbiological status of broiler carcasses during processing. J. Food Prot. 2001, 64, 179-183. [CrossRef]

8. Capita, R.; Prieto, M.; Alonsi-Calleja, C. Sampling methods for microbiological analysis of red meat and poultry carcasses. J. Food Prot. 2004, 67, 1303-1308. [CrossRef] [PubMed]

9. Velasquez, C.; Macklin, K.; Kumar, S.; Bailey, M.; Ebner, P.; Oliver, H.; Martin-Gonzalez, F.; Singh, M. Prevalence and antimicrobial resistance patterns of Salmonella isolated from poultry farms in southeastern United States. Poult. Sci. J. 2018, 97, 2144-2152. [CrossRef] [PubMed]

10. U.S. Department of Agriculture (USDA); Food Safety Inspection Service (FSIS). Roadmap to Reducing Salmonella. Driving Change through Science-Based Policy. 2020. Available online: https://www.fsis.usda.gov/sites/default/files/media_file/2020-1 2/FSISRoadmaptoReducingSalmonella.pdf (accessed on 20 April 2021).

11. Loretz, M.; Stephan, R.; Zweifel, C. Antimicrobial activity of decontamination treatments for poultry carcasses: A literature survey. Food Control 2010, 21, 791-804. [CrossRef]

12. Koutchma, T. Advances in Ultraviolet Light Technology for Non-thermal Processing of Liquid Foods. Food Bioproc. Technol. 2009, 2, 138-155. [CrossRef]

13. Hessling, M.; Gross, A.; Hoenes, K.; Rath, M.; Stangl, F.; Tritschler, H.; Sift, M. Efficient Disinfection of Tap and Surface Water with Single High Power $285 \mathrm{~nm}$ LED and Square Quartz Tube. IEEE Photonics J. 2016, 3, 7. [CrossRef]

14. Hijnen, W.; Beerendonk, E.; Medema, G. Inactivation credit of UV radiation for viruses, bacteria and protozoan (oo)cysts in water. Water Res. 2006, 40, 3-22. [CrossRef] [PubMed]

15. Lim, W.; Harrison, M.A. Effectiveness of UV light as a means to reduce Salmonella contamination on tomatoes and food contact surfaces. Food Control 2016, 66, 166-173. [CrossRef]

16. Wang, T.; MacGregor, S.; Anderson, J.; Woolsey, G. Pulsed ultra-violet inactivation spectrum of Escherichia coli. Water Res. 2005, 39, 2921-2925. [CrossRef] [PubMed]

17. U.S. Food and Drug Administration (FDA). Kinetics of Microbial Inactivation for Alternative Food Processing TechnologiesUltraviolet Light. 2013. Available online: http:/ / www.fda.gov / Food/FoodScienceResearch/SafePracticesforFoodProcesses / ucm103137.htm (accessed on 2 May 2021).

18. Morehouse, K.; Komolprasert, V. Overview of Irradiation of Food and Packaging. ACS Symposium Series 875, Irradiation of Food and Packaging. 2004; Chapter 1; pp. 1-11. Available online: https://www.fda.gov/food/irradiation-food-packaging/ overview-irradiation-food-and-packaging (accessed on 31 May 2021).

19. Koutchma, T. UV Light for Processing Foods. Ozone Sci. Eng. 2008, 30, 93-98. [CrossRef]

20. Koivunen, J.; Heinonen-Tanski, H. Inactivation of enteric microorganisms with chemical disinfectants, UV irradiation and combined chemical/UV treatments. Water Res. 2005, 39, 1519-1526. [CrossRef]

21. Matak, K.; Churey, J.; Worobo, W.; Sumner, S.; Hovingh, E.; Hackney, C.; Pierson, M. Efficacy of UV Light for the Reduction of Listeria monocytogenes in Goat's Milk. J. Food Prot. 2005, 68, 2212-2216. [CrossRef]

22. Ozer, N.; Demirci, A. Inactivation of Escherichia coli O157:H7 and Listeria monocytogenes inoculated on raw salmon fillets by pulsed UV-light treatment. Int. J. Food Sci. Technol. 2006, 41, 354-360. [CrossRef]

23. Keklik, N.; Krishnamurthy, K.; Demirci, A. Microbial Decontamination of Food by Ultraviolet (UV) and Pulsed UV Light. In Microbial Decontamination in the Food Industry: Novel Methods and Applications; Elsevier: Amsterdam, The Netherlands, 2012; pp. 344-369.

24. Bialka, K.; Demirci, A.; Puri, V. Modeling the inactivation of Escherichia coli O157:H7 and Salmonella enterica on raspberries and strawberries resulting from exposure to ozone or pulsed UV-light. J. Food Eng. 2008, 85, 444-449. [CrossRef]

25. U.S. Food and Drug Administration (FDA). Code of Federal Regulations Title 21, Part 179: Irradiation in the Production, Processing and Handling of Food. 2010. Available online: https://www.accessdata.fda.gov/scripts/cdrh/cfdocs/cfcfr/CFRSearch.cfm? CFRPart=179\&showFR=1 (accessed on 1 May 2021).

26. McLeod, A.; Hovde Liland, K.; Haugen, J.E.; Sørheim, O.; Myhrer, K.S.; Holck, A.L. Chicken fillets subjected to UV-C and pulsed UV light: Reduction of pathogenic and spoilage bacteria, and changes in sensory quality. J. Food Saf. 2018, 38, 1-15. [CrossRef]

27. Andino, A.; Hanning, I. Salmonella enterica: Survival, colonization, and virulence differences among serovars. Sci. World J. 2015, 2015, 520179. [CrossRef]

28. Lagunas-Solar, M.C.; Piña, C.; MacDonald, J.D.; Bolkan, L. Development of pulsed UV light processes for surface fungal disinfection of fresh fruits. J. Food Prot. 2006, 69, 376-384. [CrossRef] [PubMed]

29. Oms-Oliu, G.; Martín-Belloso, O.; Soliva-Fortuny, R. Pulsed Light Treatments for Food Preservation. A Review. Food Bioproc. Tech. 2010, 3, 13-23. [CrossRef]

30. Gómez-López, V.; Ragaert, P.; Debevere, J.; Devlieghere, F. Pulsed light for food decontamination: A review. Trends Food Sci. Technol. 2007, 9, 464-473. [CrossRef]

31. Kim, D.; Kang, D. Effect of surface characteristics on the bactericidal efficacy of UVC LEDs. Food Control 2020, 108, 106869. [CrossRef] 
32. Bae, Y.-M.; Lee, S.-Y. Inhibitory Effects of UV Treatment and a Combination of UV and Dry Heat against Pathogens on Stainless Steel and Polypropylene Surfaces. J. Food Sci. 2012, 77, M61-M64. [CrossRef] [PubMed]

33. Haughton, P.N.; Lyng, J.G.; Cronin, D.A.; Morgan, D.J.; Fanning, S.; Whyte, P. Efficacy of UV Light Treatment for the Microbiological Decontamination of Chicken, Associated Packaging, and Contact Surfaces. J. Food Prot. 2011, 74, 565-572. [CrossRef] [PubMed]

34. Sommers, C.H.; Sites, J.E.; Musgrove, M. Ultraviolet light $(254 \mathrm{~nm})$ inactivation of pathogens on foods and stainless steel surfaces. J. Food Saf. 2010, 30, 470-479. [CrossRef]

35. Shama, G. Ultraviolet Light. In Encyclopedia of Food Microbiology-2; Batt, C.A., Tortorello, M.L., Eds.; Academic Press: London, UK, 2014; pp. 665-671.

36. Guerrero-Beltran, J.A.; Barbosa-Canovas, G.V. Advantages and Limitations on Processing Foods by UV Light. Int. J. Food Sci. Technol. 2004, 10, 137-147. [CrossRef]

37. Shin, J.Y.; Kim, S.J.; Kim, D.K.; Kang, D.H. Fundamental characteristics of deep-UV light-emitting diodes and their application to control foodborne pathogens. Appl. Environ. Microbiol. 2016, 82, 2-10. [CrossRef] [PubMed]

38. D'Souza, C.; Yuk, H.; Hoon Khoo, G.; Zhou, W. Application of Light-Emitting Diodes in Food Production, Postharvest Preservation, and Microbiological Food Safety. Compr. Rev. Food Sci. Food Saf. 2015, 14, 719-740. [CrossRef]

39. Jarvis, P.; Autin, O.; Goslan, E.H.; Hassard, F. Application of ultraviolet light-emitting diodes (UV-LED) to full-scale drinkingwater disinfection. Water 2019, 11, 1894. [CrossRef] 